\title{
Respostas Populistas à Crise do Coronavírus: Análise dos Twitters de Donald Trump e Jair Bolsonaro
}

\author{
Andressa Liegi Vieira Costa* \\ Ana Julia Bonzanini Bernardi** \\ * Instituto Superior de Ciências Sociais e Políticas da Universidade de Lisboa, Portugal; \\ andressaliegi@hotmail.com \\ ** Universidade Federal do Rio Grande do Sul, Brasil; anajuliabbernardi@hotmail.com
}

\section{Resumo}

A pandemia do coronavírus surgiu de forma repentina, trazendo novos desafios em escala global. Brasil e Estados Unidos seguiram por meses como os dois países com mais casos e mortes por Covid-19 no mundo, até a Índia ultrapassar o Brasil, e apenas em número de casos. Além disso, encontram-se semelhanças na forma em que seus presidentes vêm lidando com a crise. Donald Trump e Jair Bolsonaro têm ganho destaque na mídia internacional pela controversa liderança frente às crises geradas pela pandemia. Ambos politizaram a crise, se posicionando contra evidências científicas e recomendações mundiais. Contrários ao isolamento social, antagonizaram governadores e prefeitos, acirrando conflitos a despeito do número de vidas perdidas, desqualificando a mídia como fake news. Visto isso, esse artigo tem como objetivo verificar como os líderes populistas, do Brasil e Estados Unidos, responderam à crise do coronavírus em termos de ações e discursos. Para isso, realizamos análise dos tweets das contas oficiais do Twitter de ambos os presidentes, no período que compreende o primeiro caso oficialmente registrado e a marca de 100 mil mortes em cada país.

Palavras-chave: Jair Bolsonaro; coronavírus; Covid-19; Donald Trump; populismo; Twitter 


\begin{abstract}
The coronavirus pandemic has suddenly and fast emerged, bringing new challenges on a global scale. Brazil and the United States have been for months the two countries with most cases and deaths by Covid-19 in the world, until India surpassed Brazil, and only on the number of cases. Therefore, there are similarities in the way their presidents have been dealing with the crisis. Donald Trump and Jair Bolsonaro have been in standout on international media by their poor leadership in face of the crises created by the pandemic. Both presidents have politicized the crisis, standing against scientific evidence and world recommendations. Contrary to social isolation, they have antagonized governors and mayors, intensifying conflicts despite the lost lives, disqualifying the media as fake news. Given that, this paper aims to analyse how the populist leaders, in Brazil and in the United States, have responded to the coronavirus crisis in terms of actions and discourses. For this purpose, we analyse tweets from both their official Twitter accounts, on the period from the first official recorded case until the milestone of 100 thousand deaths in each country.
\end{abstract}

Keywords: Brazil; coronavirus; Covid-19; United States; populism; Twitter

\title{
1. Introdução
}

O novo coronavírus, causador da Covid-19, foi decretado pela Organização Mundial da Saúde (OMS) como uma pandemia em 11 de março de 2020. O vírus, além de ter se espalhado rapidamente pelo mundo, também resultou em respostas diversas a seus impactos por parte dos governos. Após a China e a Europa, os Estados Unidos se tornou o novo epicentro em abril, com o Brasil atingindo a segunda posição em número de infectados em maio, e em número de mortes em junho. No momento em que finalizamos este artigo, em setembro, a Índia tomava a segunda posição (WHO,2020).

Além do alto número de contágio pelo coronavírus, Estados Unidos e Brasil também guardam em comum certas características e posicionamentos de seus líderes. Tanto Donald Trump quanto Jair Bolsonaro subestimaram a seriedade do vírus, contrariando recomendações da OMS e da comunidade científica (Rachman, 2020). Dadas suas características populistas, politizaram a crise da Covid-19, aprofundando a polarização política preexistente nos dois países. Ambos são conhecidos por espalhar desinformação e notícias falsas, uma vez que ambos os líderes têm a presença digital como uma marca central de sua plataforma política (Costa \& Bernardi, 2020).

Ainda que não seja possível falar em uma única "resposta populista" à crise do coronavírus (Mudde, 2020), o caso do Brasil e dos Estados Unidos nos permite apontar uma série de semelhanças que permitem a construção de paralelos e a análise dos possíveis efeitos de governos populistas em uma crise mundial de saúde pública. Nesse sentido, argumentamos que o Brasil e os Estados Unidos estão lutando contra duas epidemias: a do coronavírus e a do populismo, e que estas juntas podem ter um efeito nocivo para suas sociedades (Costa \& Bernardi, 2020). 
Neste artigo busca-se verificar como os líderes populistas, do Brasil e Estados Unidos, responderam à crise do coronavírus em termos de ações e discursos. Para isso, primeiramente estuda-se os casos do Brasil e dos Estados Unidos, observando os principais acontecimentos e ações de seus governantes de modo a identificar como estes reagiram durante a pandemia. Na sequência, realiza-se uma análise dos tweets de Donald Trump e Jair Bolsonaro, em suas contas oficiais, no período que compreende o registro oficial do primeiro caso e a marca de cem mil mortes em cada país, com o objetivo de averiguar como os elementos observados anteriormente se encontram empiricamente nos discursos dos líderes no ambiente digital do Twitter. Assim, serão apresentados resultados iniciais sobre corpus de tweets em questão. Primeiramente, será observado o panorama geral da amostra através de nuvens de palavras para cada governante, que compreende todos os tweets relacionados à pandemia no período mencionado. Por fim, realiza-se uma análise comparativa entre os tweets mais compartilhados dos dois governantes e suas abordagens. Finalmente, apresenta-se algumas considerações finais de modo a analisar os dois casos de forma comparativa.

\section{A pandemia do coronavírus e os desafios para governantes globais}

No final de dezembro de 2019, a cidade de Wuhan, na China, registrou diversos casos de pneumonia com origem desconhecida. Em 7 de janeiro, foi anunciado oficialmente que um novo vírus havia sido identificado, sendo pertencente à família dos coronavírus. A primeira morte ocorreu dois dias depois no país. Diversas cidades foram postas em lockdown, afetando milhões de pessoas. Ainda assim, em 30 de janeiro, o vírus já estava presente em dezoito países fora da China. Em 11 de março de 2020, a Organização Mundial da Saúde declarava que a Covid-19 se tratava de uma pandemia (WHO, 2020).

Enquanto a Itália se tornou o primeiro país ocidental a registrar o vírus em 21 de fevereiro, um mês depois a Europa havia se tornado o epicentro da epidemia (WHO, 2020; Al Jazeera, 2020a). O vírus se espalhou rapidamente, alcançando 181 países em maio (Mena, DeLuca \& Yukari, 2020). Em março, o EUA passou a ser o país com maior número de casos no mundo e, em abril, o com mais mortes, e o Brasil assumiu a segunda posição para ambos os casos em junho. A situação manteve-se assim até 7 de setembro, quando a Índia assumiu o segundo lugar, porém apenas em números de casos (Worldmeter, 2020).

Enquanto governantes mundiais têm se debruçado exaustivamente sobre medidas para conter a expansão do coronavírus e aliviar os efeitos da crise para a população, ainda há os que minimizem a situação e vão na contramão das recomendações de organizações internacionais (Rachman, 2020). Ainda que não seja possível se falar em uma única "resposta populista" à crise do coronavírus, uma vez que governos populistas no mundo apresentaram respostas diferentes (Mudde, 2020), conforme Levitsky e Ziblatt (2018), períodos de crise facilitam a concentração e abuso de poder por parte de líderes populistas demagogos, uma vez que os cidadãos se tornam mais 
dispostos a tolerar e apoiar medidas autoritárias. Os efeitos da pandemia na democracia não tendem a ser uniformes. Enquanto para alguns casos, a má gestão da crise pode facilitar a ascensão ao poder de líderes autoritários, também é possível que enfraqueça líderes populistas que já se encontram no poder, por tornar sua incapacidade e irresponsabilidade mais aparentes (Bitar \& Zovatto, 2020).

\section{Populismo, pandemia e o ambiente digital: análise dos tweets de Jair Bolsonaro e Donald Trump}

De acordo com Finchelstein (2020), o populismo atual é um fascismo adaptado à lógica e ao contexto democrático. O populismo se mostra como o oposto do pluralismo na política, uma vez que fala em nome de uma maioria imaginária, rechaçando todas as opiniões que considera minoria em prol de um nacionalismo extremista, que pretende colocar o seu país "acima de todos" (Finchelstein, 2020, p. 17). Para Urbinati (2020), a característica comum a todos líderes populistas é que eles se colocam como "anti-establishment" atuando como os legítimos representantes dos interesses do "povo". Fuchs (2018), ao estudar o autoritarismo de extrema-direta, aponta que líderes demagogos, como Donald Trump, utilizam-se de inseguranças e medos provenientes de crises sociais, políticas e econômicas para desviar a atenção do motivo dessas crises ao formar bodes expiatórios e discursos nacionalistas e estabelecer sua ordem social. Urbinati (2019) fala sobre a existência de uma 'democracia populista', um teste de um novo tipo de democracia representativa, baseada na relação direta do líder com aqueles a quem define como "o povo", com a presença de uma autoridade superlativa por parte da audiência. Assim, tem como alvo as instituições intermediárias como partidos políticos e a mídia, resultando na política da parcialidade (p. 4).

Pajnik e Meret (2018) falam sobre o processo de mediatização da comunicação política, que se refere tanto “à integração da mídia nas esferas política, cultural, social e econômica quanto à crescente importância da mídia como uma própria instituição" (p. 36). Quanto mais os partidos políticos se distanciam da publicidade democrática, mais se vê a presença da "política de espetáculo" e mais se emprega a retórica populista e a propaganda como meios de obter atenção do público. A miditiazação da política faz parte de um processo mais amplo de miditiazação da sociedade, que tem como consequência “democracias dirigidas pela mídia”, em que a mídia de massa absorve a função de instituições políticas (Pajnik \& Meret, 2018). Apesar da semelhança com nacionalismos e autoritarismos do passado, a emergência de novas tecnologias leva o autoritarismo de extrema-direita contemporâneo a utilizar-se de novos formatos para comunicação, como as redes sociais (Fuchs, 2018). Nesse contexto, é importante relembrar da emergência da era da pós-verdade, marcada pelo crescente uso de fake news, que afeta as bases da democracia, e refere-se às circunstâncias nas quais fatos objetivos são menos influentes do que a emoção e crenças pessoais em moldar a opinião pública (Farkas \& Schou, 2020). 


\subsection{Opções metodológicas}

Com o avanço das redes sociais como forma de comunicação e obtenção de informação, o Twitter foi descrito como um palanque online para políticos se comunicarem diretamente com o seu eleitorado, sem a interferência da mídia tradicional (Van Djick, 2013). Para políticos populistas como Jair Bolsonaro e Donald Trump, que criminalizam o jornalismo profissional, inclusive bloqueando pessoas contrárias ao seu governo, o Twitter se materializou como uma rede essencial de contato direto com os seus apoiadores sobre as ações tomadas em seus governos justamente pela ressonância que a rede permite nas discussões políticas (Rosseto, Carreiro \& Almada). Ademais, os Estados Unidos possuem 62,5 milhões de usuários do Twitter, e o Brasil 15,7 milhões (Statista, 2020) sendo um interessante campo para pesquisa.

Para a elaboração deste artigo foram analisados os tweets das contas oficiais de Jair Bolsonaro (@jairbolsonaro) e Donald Trump (@realDonaldTrump). Os dados compreendem o período entre o primeiro caso de Covid-19 registrado oficialmente e o alcance da marca de 100 mil mortes em cada país. Assim, para o Brasil o período engloba de 26 de fevereiro à 9 de agosto ${ }^{[1]}$ de 2020, e para os Estados Unidos de 21 de janeiro a 29 de maio ${ }^{[2]}$ de 2020. Dado o período, a amostra do Brasil contou com 1406 tweets, que após terem sido classificados e separados entre os que possuíam relação com a temática da pandemia, totalizaram 642. A amostra dos Estados Unidos contou com 4307 tweets que, após devida classificação, totalizaram 1202.

Em seguida, os tweets foram categorizados de acordo com os elementos observados sobre as ações de Donald Trump e Jair Bolsonaro, já estabelecidas como características populistas a partir da literatura atual sobre o tema (Finchelstein, 2020; Urbinati, 2019; Pajnik \& Meret, 2018; Levitsky \& Ziblatt, 2018). As categorias utilizadas foram as seguintes: ações do governo, ataque à mídia, ataque a opositores, cooptação do termo fake news, oposição às medidas de contenção, defesa da economia, ataque a governadores e prefeitos, mobilização de apoiadores, nacionalismo, desinformação/ informações falsas, "chinese virus" ou vírus chinês e defesa de tratamentos sem comprovação científica.

Primeiramente, apresenta-se e analisa-se as nuvens de palavras com os tweets de cada governante, seguidas pelo estudo dos 10 tweets mais compartilhados de cada um dos presidentes, assim podendo compreender quais publicações tiveram maior engajamento.

1. Apesar de o número de 100 mil mortes ter sido alcançado em 8 de agosto de 2020 , os tweets do dia 9 também foram adicionados, uma vez que envolvem respostas do presidente em relação às críticas perante sua postura ao atingir a marca no dia anterior.

2. Nos Estados Unidos, a marca de 100 mil mortes foi alcançada em 27 de maio de 2020. Entretanto, optou-se por avaliar até a data de 29 de maio quando Donald Trump anuncia a saída dos Estados da Unidos da Organização Mundial da Saúde (OMS). 


\subsection{Brasile @jairbolsonaro}

O primeiro caso de Covid-19 registrado no Brasil ocorreu em 26 de fevereiro. Em seu primeiro pronunciamento, em 6 de março, Jair Bolsonaro afirmou que não havia motivo para pânico (Matoso \& Rodrigues, 2020). No dia 23 de março foram impostas restrições à entrada de estrangeiros, ao passo que o número de casos de Covid-19 se aproximava de 2.000. Enquanto o Ministério da Saúde publicitava compras de testes e reforçava o pedido de isolamento social da população, Bolsonaro defendia o fim do isolamento e a volta à normalidade. No dia 26 de março a Câmara dos Deputados aprovou um auxílio emergencial de 600 reais para trabalhadores informais, prevendo inicialmente três meses de auxílio (Cucolo, 2020), que acabou por ser prorrogado e ainda estar em vigor quando da escrita deste artigo, setembro de 2020, ainda que seja debatida uma diminuição em seu valor.

Em pronunciamento nacional no dia 24 de março, Bolsonaro passou a criticar governadores e prefeitos pelo fechamento do comércio e medidas de confinamento. Além disso, acusou a mídia de estar gerando pavor e histeria na sociedade. Ao subestimar os efeitos do vírus, se referiu a ele como apenas uma "gripezinha", alegando de forma caricata que se o contraísse nada aconteceria devido a seu "histórico de atleta" (Jornal Nacional, 2020). Desde então uma série de carreatas e manifestações contra o isolamento social ocorreram em todo o país, algumas com a participação do presidente (Carvalho \& Costa, 2020).

A desinformação e as fake news continuaram durante a pandemia, muitas endossadas pelo próprio presidente e líderes do governo. A defesa de Bolsonaro ao uso da cloroquina como forma de prevenção e cura da Covid-19 chegou a deixar as farmácias sem estoques (Libório \& Favero, 2020). O presidente teve publicações suspensas no Twitter, Facebook e Instagram por espalhar notícias falsas sobre a pandemia (Folha de S. Paulo, 2020). Eduardo Bolsonaro, deputado federal e filho do presidente, em ode ao pronunciamento de Trump que chamou o coronavírus de vírus chinês, insinuou em sua conta pessoal do Twitter que a China havia tardado em relatar o coronavírus ao mundo com medo do desgaste político. O então Ministro da Educação, Abraham Weintraub, proferiu afirmações xenófobas de que a China era culpada pela pandemia, sendo posteriormente investigado pelo ocorrido (Falcão \& Vivas, 2020).

Desde o início da crise do coronavírus no Brasil, houve três trocas no Ministério da Saúde, pelo simples fato de os Ministros seguirem as recomendações da OMS e serem contrários à implementação do protocolo de uso da cloroquina no tratamento de pacientes com Covid-19. Henrique Mandetta liderou o Ministério desde o início do governo, e durante os dois primeiros meses da pandemia no país. Ao ver a popularidade do ministro crescer nas redes sociais, Bolsonaro iniciou um confronto direto dentro, buscando forçar sua demissão. Em 16 de abril, Mandetta foi demitido e substituído por Nelson Teich, quando a pandemia já somava mais de $30 \mathrm{mil}$ infectados e cerca de 2 mil mortos (Mazuí, 2020). Teich não completou um mês como ministro, pois mostrou-se contrário ao uso da cloroquina. Com a justificativa de que 
os ministros precisam estar alinhados ao seu discurso, Bolsonaro escolheu o General Eduardo Pazuello como ministro interino da Saúde.

Em 19 de maio, o Brasil bateu seu recorde no número de mortes: foram 1.179 vidas perdidas em $24 \mathrm{~h}$. No mesmo dia, em uma live nas suas redes sociais, Bolsonaro mencionou que Trump estava tomando cloroquina preventivamente e anunciou que novo protocolo para uso da cloroquina no Brasil seria assinado, que foi implementado no dia seguinte pelo General Pazuello, sem formação na área médica, indo em direção contrária a diversos estudos científicos que, além de não demonstrarem resultados positivos no uso do medicamento, também indicam que pode aumentar os riscos de morte (Uribe \& Carvalho, 2020).

Em meio às trocas no Ministério da Saúde, novas ondas de manifestações contra o isolamento social foram registradas. Em 19 de abril, atos foram realizados em diversas cidades do país por apoiadores de Bolsonaro. Os atos defendiam uma intervenção militar, e pediam o fechamento do Congresso e do Supremo Tribunal Federal. O ato em Brasília contou a presença de Bolsonaro, que, sem máscara, discursou para a multidão, ressaltando seu caráter populista com frases como "agora é o povo no poder" e "o que tinha de velho ficou para trás", referindo-se ao que chama de "velha política" (G1, 2020a).

Tais atitudes de Jair Bolsonaro deixam claro seu caráter populista, uma vez que estes alegam ser a voz do povo. Além disso, é possível observar o elemento de abdicação coletiva por parte dos apoiadores, processo pelo qual há transferência da autoridade para um líder que ameaça a democracia (Levitsky \& Ziblatt, 2018). Entretanto, as manifestações de Bolsonaro foram rechaçadas tanto pelos líderes do Legislativo quanto do Judiciário. Nos dias seguintes, Bolsonaro fala publicamente à imprensa dizendo que é a favor da liberdade e que "defende um STF e Congresso abertos e transparentes". No entanto, ao criticar as prisões realizadas por pessoas que estavam violando a quarentena, o presidente volta a mostrar seu caráter autoritário e personalista, ao afirmar que "Eu [Bolsonaro] sou realmente a Constituição" (G1, 2020b).

De acordo com o V-Dem (Varieties of Democracy), o Brasil encontra-se como um país com alto risco de retrocesso democrático durante a pandemia (Lührmann, Edgell \& Maerz, 2020). A insistência de Bolsonaro em contrariar laudos científicos, e orientações de órgãos especializados, como a OMS, fez com que o presidente ganhasse notoriedade internacional como "possivelmente a maior ameaça à resposta à Covid-19 no Brasil” (The Lancet, 2020, p. 1461). Em julho, após testar positivo para a Covid-19, Bolsonaro tornou-se de vez o "garoto propaganda" da cloroquina, fazendo lives com uma caixa do medicamento a seu lado (Andrade, 2020), e levantando o medicamento como troféu para apoiadores em frente do Palácio do Planalto (Murakawa, 2020). Em 8 de agosto, ao atingir a marca de 100 mortes no país, o presidente, em live, lamentou a morte "por qualquer seja a causa", além de utilizar-se erroneamente de um artigo de jornal britânico para dizer que o lockdown havia matado mais que a própria Covid (Weterman, 2020). 
Após elencados os principais acontecimentos que marcaram a pandemia do coronavírus no Brasil, a seguir iremos observar empiricamente como as ações de Jair Bolsonaro se refletem em sua retórica na sua conta oficial do Twitter. Primeiramente, observaremos uma nuvem de palavras, produzida a partir das 1.803 palavras encontradas nos tweets de Jair Bolsonaro, que evidencia os principais temas e abordagens do presidente em seus tweets:

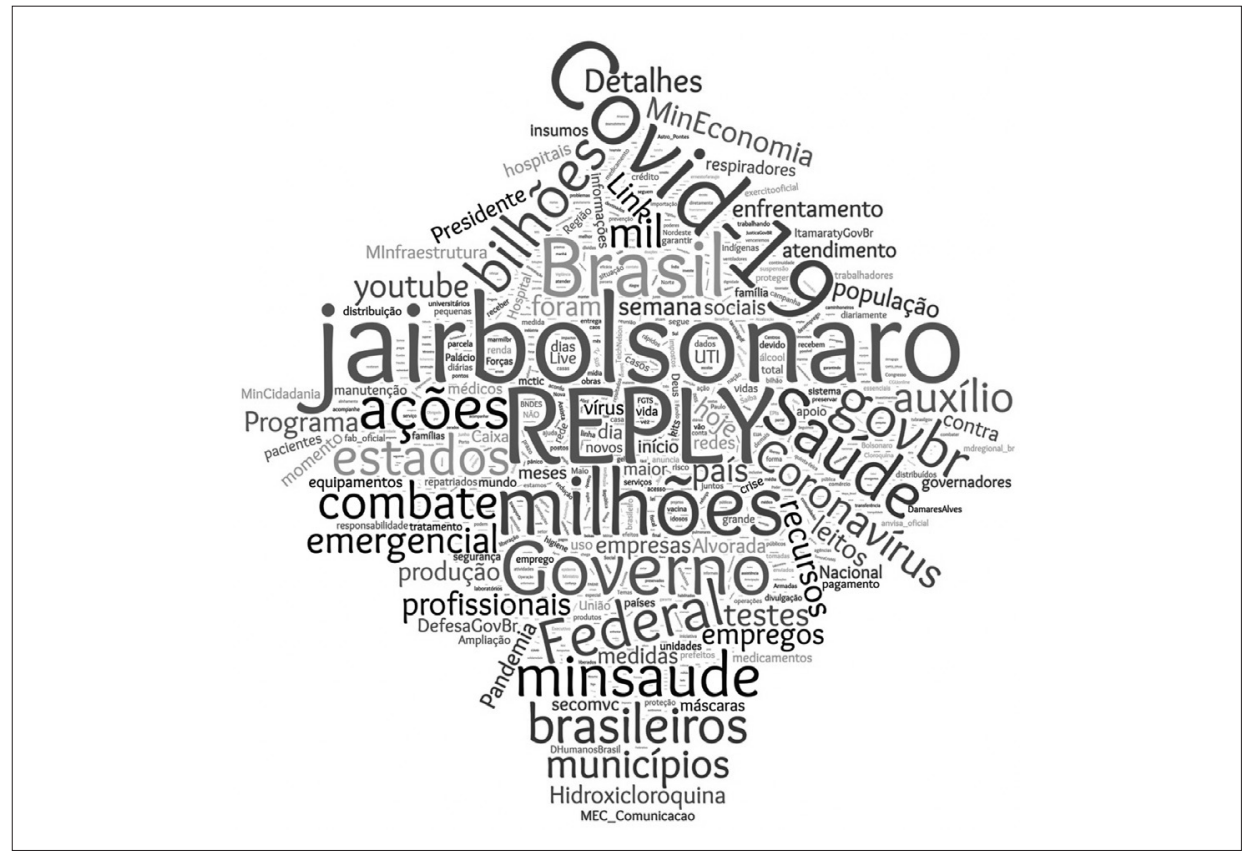

Figura 1. Nuvem de Palavras: Tweets da Conta Oficial de Jair Bolsonaro relacionados ao Coronavírus

Fonte: Elaborado pelas autoras.

Na Figura 1, acima, podemos observar as palavras mais utilizadas por Jair Bolsonaro durante o período estudado. Primeiramente, o uso da palavra "reply" (usada 299 vezes) se justifica pela forma como Bolsonaro utiliza seu Twitter. A maioria dos seus tweets analisados no período refere-se à divulgação de ações de seu governo (411 no total - presente em $64 \%$ dos tweets da amostra), o que é evidenciado por palavras como "ações" (usada 69 vezes), "medidas" (26 vezes) e "recursos" (38 vezes), entre outras. $\mathrm{O}$ modo como Bolsonaro informa seus seguidores se dá pela postagem de um tweet e criação de um thread/fio (através do uso da ferramenta reply em seu próprio tweet) no qual divulga uma lista de ações. Destaca-se a questão do Auxílio Emergencial (palavras usadas 49 e 44 vezes, respectivamente) de 600 reais, que se 
torna cada mais vez mais frequente em suas postagens durante o período, o que pode ser explicado pelo aumento da popularidade de Bolsonaro em pesquisas de opinião, puxado pela concessão do benefício, o que também permitiu ao presidente penetrar nas camadas populares das regiões mais pobres do Brasil, que tradicionalmente são espaço do Lula e do PT (Ferreira \& Fragelli, 2020).

Ao divulgar suas ações pelo Twitter, Bolsonaro frequentemente se refere a este como fonte verídica de informações, alegando que a mídia apenas divulga "fake news" sobre ele e seu governo. Na amostra estudada, foram encontrados 34 tweets com ataque à mídia, 5,3\% de suas postagens da amostra. Nessas, a mídia é relacionada à esquerda, acusada de desinformar, fazer demagogia e gerar pânico, e observam-se com frequência ataques, especialmente à Rede Globo. Na mesma linha, Bolsonaro ataca prefeitos e governadores em 22 de seus tweets (aproximadamente 3,5\%). Nesses tweets, Bolsonaro alega que os governantes locais estariam tentando destruir o país ao utilizarem-se de medidas de restrição para contenção da pandemia, as quais o presidente considera extremas e que estariam restringindo a liberdade dos cidadãos, relembrando que sua autonomia ocorre em função de decisão do STF. Igualmente, em 12 tweets (cerca de 2\%), Bolsonaro ataca velhos adversários, como a Venezuela, governos anteriores (que chama de corruptos), Lula, o PT, Fernando Haddad e Fernando Henrique Cardoso. Na mesma linha, em 42 tweets (mais de 6,5\%) Bolsonaro expõe críticas às medidas de contenção. Nesses, Bolsonaro salienta a necessidade de proteger empregos e a economia, em alguns defendendo o isolamento vertical (apenas de grupos de risco), colocando-se como defensor da população que quer trabalhar, e utilizando-se de slogans como "O Brasil não pode parar".

O presidente também apresenta 76 tweets (quase 12\%) de mobilização de apoiadores. Nesses, Bolsonaro normalmente aparece na rua conversando com a população, o que ocorre em aglomerações, nas quais muitas vezes o presidente sequer utiliza máscara ou segue medidas de segurança Além de utilizar as palavras Covid-19 133 vezes e coronavírus 49 vezes, nota-se também na o uso da palavra "hidroxicloroquina” (27 vezes), que se refere a seus tweets de divulgação do remédio para tratamento da Covid-19, mesmo sem comprovação científica. Estes totalizaram 53, estando o assunto presente em mais de $8 \%$ dos tweets analisados. Estas postagens envolvem especulações sobre sua eficácia, a implementação de protocolo para seu uso no país, seu uso após o presidente contrair a doença (sempre de modo a evidenciar sua eficácia), além de relatos de médicos que aprovam a utilização do tratamento. Do mesmo modo, foram também identificados 20 tweets (acima de 3\%) com algum tipo de desinformação, o que para os fins desse estudo foi entendido como informações tendenciosas ou sem apresentação de qualquer tipo de fonte. Nesses, fala que o Brasil estaria investindo mais no enfrentamento da crise do que qualquer outro país do mundo, utiliza-se de informações como o número de mortes por milhão de habitantes para dizer que o Brasil estaria em uma boa situação da pandemia comparado a outros países, traz dados sobre a eficácia do uso da cloroquina sem fontes ou com fontes duvidosas (como alguns denominadas como “jornalismo independente” e já 
conhecidas por propagarem fake news), e também justifica a omissão dos números diários da Covid-19 no país com uma metodologia que sobressairia o número de curados sem explicar bem do que se trata.

Tabela 1. Os 10 Tweets mais retweetados de Jair Bolsonaro durante o período

\begin{tabular}{|c|c|c|c|c|}
\hline & Data & Tweet & Retweets & Categoria(s) \\
\hline 1 & $17 / \mathrm{abr}$ & $\begin{array}{l}\text { Determinei à @CGUonline, órgão federal responsável } \\
\text { pela fiscalização dos gastos públicos, que atue } \\
\text { preventivamente, permitindo que os recursos cheguem } \\
\text { de maneira segura ao usuário final, o povo brasileiro. O } \\
\text { governo federal já empenhou R\$ } 140 \text { bilhões no combate } \\
\text { ao covid-19. }\end{array}$ & 24482 & Ações de governo \\
\hline 2 & 9/jun & $\begin{array}{l}\text { - Após pedirem desculpas pela Hidroxicloroquina, } \\
\text { agora a OMS conclui que pacientes assintomáticos (a } \\
\text { grande maioria) não têm potencial de infectar outras } \\
\text { pessoas. Milhões ficaram trancados em casa, perderam } \\
\text { seus empregos e afetaram negativamente a Economia }\end{array}$ & 22609 & $\begin{array}{l}\text { Defesa de tratamentos } \\
\text { sem comprovação } \\
\text { científica/Ataque a } \\
\text { adversários/Críticas a } \\
\text { medidas de contenção }\end{array}$ \\
\hline 3 & 7/abr & https://t.co/DW6qTzfVMU https://t.co/sBwTWmsd4K & 21317 & Ataque a adversários \\
\hline 4 & $26 /$ mar & $\begin{array}{l}\text { É mais fácil fazer demagogia diante de uma população } \\
\text { assustada, do que falar a verdade. Isso custa popularidade. } \\
\text { Não estou preocupado com isso! Aproveitar-se do medo } \\
\text { das pessoas para fazer politicagem num momento como } \\
\text { esse é coisa de COVARDE! A demagogia acelera o caos. }\end{array}$ & 20484 & Ataque à mídia \\
\hline 5 & $17 / \mathrm{abr}$ & $\begin{array}{l}\text { — Minha solidariedade ao cantor @gusttavo_lima, que } \\
\text { vem sendo injusta e covardemente atacado após a grande } \\
\text { live que fez dentro de sua própria casa. Ele e outros } \\
\text { artistas sertanejos e de demais gêneros, têm sido grandes } \\
\text { heróis nessa luta contra a COVID19 e merecem aplausos! }\end{array}$ & 18534 & Ataque à mídia \\
\hline 6 & $21 / \operatorname{mar}$ & $\begin{array}{l}\text { - Hospital Albert Einstein e a possível cura dos } \\
\text { pacientes com o Covid-19. https://t.co/Aia4RzTVlp }\end{array}$ & 17989 & $\begin{array}{c}\text { Defesa de tratamentos } \\
\text { sem comprovação } \\
\text { científica }\end{array}$ \\
\hline 7 & $8 /$ jun & $\begin{array}{l}\text { - Lembro à Nação que, por decisão do STF, as ações } \\
\text { de combate à pandemia (fechamento do comércio e } \\
\text { quarentena, p.ex.) ficaram sob total responsabilidade dos } \\
\text { Governadores e dos Prefeitos. }\end{array}$ & 16918 & $\begin{array}{l}\text { Ataque a } \\
\text { governadores/ } \\
\text { prefeitos }\end{array}$ \\
\hline 8 & $18 /$ mar & $\begin{array}{l}\text { - Informo que meu } 2 .^{\circ} \text { teste para COVID-19 deu } \\
\text { NEGATIVO. - Boa noite a todos. }\end{array}$ & 16739 & Outro \\
\hline 9 & $19 /$ mar & $\begin{array}{l}\text { Nunca abandonarei o povo brasileiro, para o qual devo } \\
\text { lealdade absoluta! Boa noite a todos! }\end{array}$ & 16708 & Outro \\
\hline 10 & $1 / \mathrm{abr}$ & $\begin{array}{l}\text { - Juntos, com coragem, serenidade e patriotismo, } \\
\text { venceremos a batalha contra essa epidemia e seus efeitos! } \\
\text { Lutaremos com todas as nossas forças para proteger a } \\
\text { nossa nação! NENHUM BRASILEIRO FICARÁ PARA } \\
\text { TRÁS! }\end{array}$ & 16680 & Nacionalismo \\
\hline
\end{tabular}

Fonte: Elaborado pelas autoras. 
Na Tabela 1, acima, observamos os dez tweets mais compartilhados de Jair Bolsonaro. Primeiramente, notamos que, apesar de a grande maioria dos tweets de Bolsonaro no período serem relacionado à divulgação de ações de governo, e o tweet mais retweetado pertencer a esta categoria, todos os outros englobam outras temáticas. Vemos também que o segundo tweet mais compartilhado se refere à defesa do tratamento da Covid-19 com hidroxicloroquina, além de criticar as medidas de contenção e a OMS. O terceiro tweet é uma resposta de Bolsonaro a um tweet de Haddad (primeiro link) que diz "Nunca tinha visto um presidente se colocar em situação tão humilhante", relacionado à possível demissão do ex-Ministro da Saúde, Henrique Mandetta. O conteúdo da resposta é uma imagem (segundo link) de Lula sendo escoltado pela polícia. O quarto tweet se trata de um dos diversos ataques de Bolsonaro à mídia, a qual acusa de fazer demagogia e politicagem, gerando caos. O quinto tweet refere-se a um incidente ocorrido com o músico sertanejo Gustavo Lima, que após fazer uma live foi criticado por beber álcool em demasia e falar palavrões. Bolsonaro utiliza-se de sua comum retórica para defender o cantor que estaria sendo "atacado pela mídia”. O sexto tweet apresenta um vídeo de Bolsonaro falando sobre um protocolo de pesquisa iniciado no Hospital Albert Einstein para verificar a eficácia do uso da cloroquina em pacientes com Covid-19 e, na sequência, de que havia decidido, junto com o Ministro da Defesa, que o Laboratório Químico Farmacêutico do Exército deveria iniciar imediatamente ampliar a produção do medicamento, que não poderia ser vendido para outros países, uma vez que também serve para o tratamento de outras doenças como a malária e a artrite. Assim, destaca-se que mesmo sem estudos conclusivos, Bolsonaro pressiona a sua produção em larga escala, e como é um traço seu, faz planejamentos e encontra respaldo em setores do Exército para implementar suas políticas. O sétimo tweet passa clara e detalhadamente a responsabilidade da crise causada pela pandemia ao Supremo Tribunal Federal (STF) e aos governadores e prefeitos. Com esse tipo de afirmação, Bolsonaro visa manter sua imagem e popularidade, utilizando-se de uma retórica comumente utilizada por líderes populistas, de criar um ou mais inimigos que o impediriam de fazer o país prosperar. $\mathrm{O}$ oitavo tweet diz respeito à primeira suspeita de ter contraído a Covid-19 em março de 2020, quando diversos integrantes da comitiva brasileira que foi aos Estados Unidos testaram positivo para a doença. O nono tweet aponta o já comum apelo ao nacionalismo e patriotismo por parte do presidente, em uma mensagem que o põe ao lado do povo, outro traço comum de líderes populistas, o que também aparece no décimo, e último, tweet em uma mensagem de defesa da nação.

\subsection{Estados Unidos e @realDonaldTrump}

O primeiro caso de Covid-19 confirmado nos Estados Unidos ocorreu em 21 de janeiro de 2020. Após criar uma equipe de trabalho para o coronavírus em 29 de janeiro, Trump baniu todos os voos da China. Desde o começo, Trump alegava que a situação estava sob controle no país. Em 4 de março, o governo aprovou um projeto de lei emergencial inicial de 8.3 bilhões de dólares, além do maior projeto da história 
americana, de 2.2 trilhões, garantindo 1.200 dólares de auxílio por indivíduo. Após receber críticas sobre sua administração da crise, Trump criticou Obama dizendo que ele "não fez nada" quando ocorreu a gripe suína (H1N1 - Influenza). Em 11 de março, foi decretada a proibição de voos provenientes da Europa, o então novo epicentro da epidemia (Al Jazeera, 2020b).

Os tweets de Donald Trump expressam com clareza a linha do tempo da Covid-19 aos olhos do presidente e da mídia conservadora. No período analisado, o presidente twittou 1.202 vezes sobre a Covid-19. Destes posts, 237 citavam ações do governo sobre a Covid-19, 116 representavam ataques à mídia tradicional e 110 ataques à opositores políticos do presidente. Abaixo, na Figura 2, apresentamos a nuvem de palavras produzida a partir das 1.466 palavras encontradas nos tweets de Donald Trump:

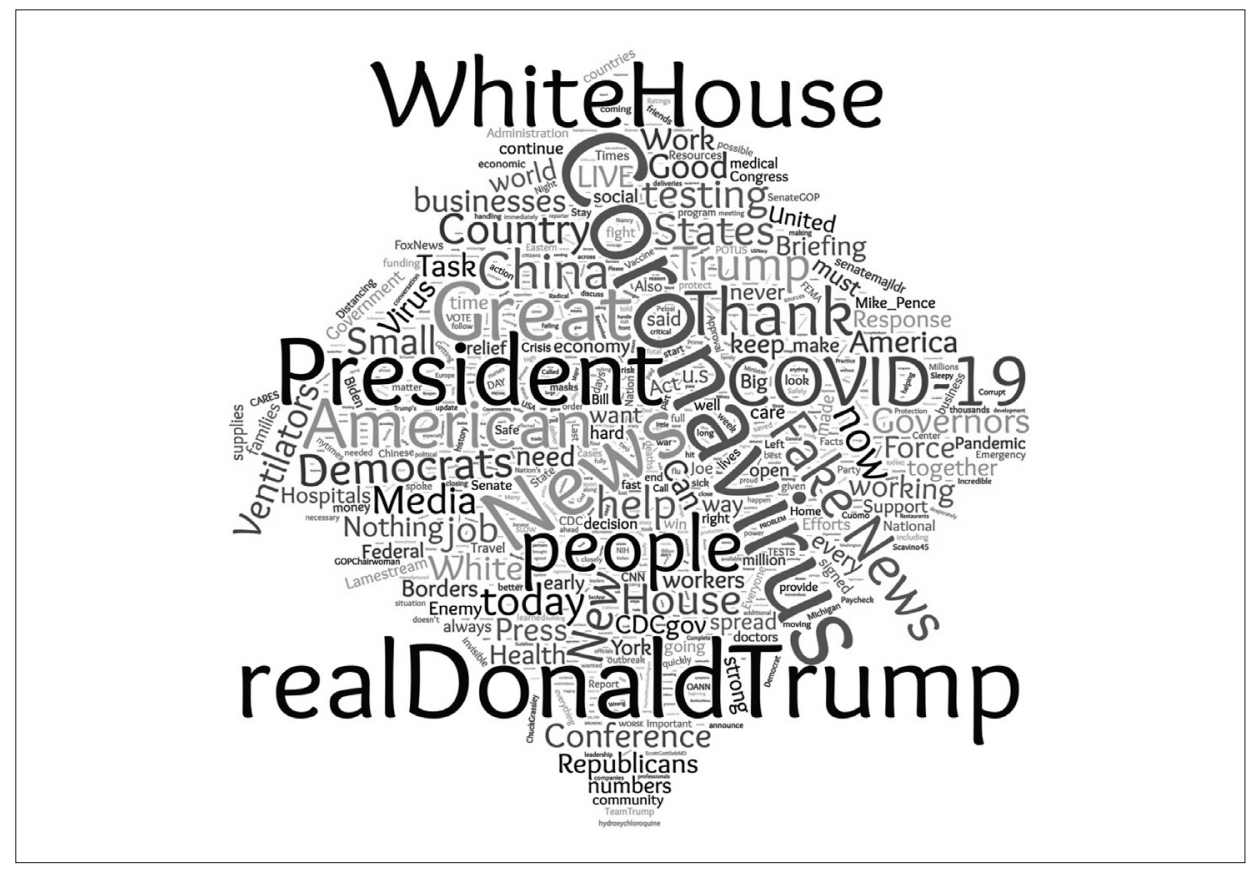

Figura 2. Nuvem de Palavras: Tweets da Conta Oficial de Donald Trump relacionados ao Coronavírus

Fonte: Elaborado pelas autoras.

As palavras que mais se repetem nesta amostra de tweets sobre o Covid-19 revelam um pouco a lógica de comunicação utilizada pelo presidente Donald Trump. A palavra mais citada foi Coronavírus (243), seguida pelo user do presidente @realDonaldTrump (153), uma vez que Trump chega a retweetar até três vezes seus posts, como também os da @WhiteHouse (133) e de seus apoiadores. A maior parte dos 
tweets analisados no período fazem referência às ações do governo sobre a pandemia (quase 30\%) e cerca de 10\% específico de ações institucionais no combate à Covid-19. Entre as principais palavras se encontram Great (127), people (108), American (102), uma vez que o presidente se utiliza da temática nacionalista e do seu bordão de campanha "Make America Great Again". Fora as ações de governo, as categorias que tiveram maior volume de tweets foram os ataques a opositores (cerca de $25 \%$ ) e ataques à mídia (cerca de 15\%).

Outras palavras recorrentes são News (129) e Fake News (88), uma vez que os ataques à mídia são frequentes, muitas vezes cooptando o termo "Fake News" (cerca de $10 \%$ da amostra) para se referir aos principais canais de notícias, os quais o presidente também chama de Lame Stream Media (23). A maioria conservadora também atribuiu a culpa da crise do coronavírus à mídia tradicional, que alegavam estar trabalhando para denegrir a imagem política de Trump ao tentar mostrar que o presidente não estaria fazendo o suficiente para combater a propagação do vírus. Assim, acusam a mídia de criar histeria com o intuito de influenciar nas eleições presidenciais (Zurcher, 2020). Uma pesquisa realizada pela Axios (Cohen, 2020), entre 5 e 9 de março, mostrou que $62 \%$ dos Republicanos acreditavam que as notícias sobre a seriedade do coronavírus eram exageradas, contra 31\% dos Democratas, e $44 \%$ da população geral. Ainda nesse período, $43 \%$ aprovava a resposta de Trump ao coronavírus, contra 49\% de desaprovação, também apresentando divergências entre espectros políticos - 87\% de aprovação entre Republicanos e 83\% de desaprovação entre Democratas (Quinnipiac University, 2020).

O primeiro tweet de Trump sobre o coronavírus aparece em 24 de janeiro, quando o presidente menciona que a China (76) está fazendo um bom trabalho em conter o vírus (45) e informa que os Estados Unidos, apesar de terem poucos casos reportados, estão monitorando atentamente o avanço da Covid-19 (99). Com o avanço da pandemia, Trump passa a atacar de forma mais crítica tanto a China como a OMS, mencionados como críticos de seu governo, e utilizar o termo "Chinese vírus" (13). Seguido por acusações de que seria uma conotação racista, Trump justificou o uso do termo dizendo que essa era a origem do vírus e ele queria ser preciso (Forgey, 2020). Ao longo do mês de fevereiro o presidente faz poucas menções sobre a força tarefa e o avanço da pandemia - concentrando seus tweets no processo de impeachment que estava sendo votado. Em março, Trump anuncia que doaria o seu salário integralmente para ações de controle da pandemia, além da aprovação pelo Congresso do pacote de 8 bilhões de dólares para ações de controle da pandemia - assim, as postagens sobre a Covid-19 tornam-se diárias, e podemos observar o aumento do uso das palavras "ventilators" (ventiladores) (52), "testing" (testes) (59) e "help" (ajuda) (61).

No início de abril, Trump passou a atacar a OMS, escolhendo seu novo inimigo político, alegando que a organização não teria sido suficientemente agressiva em suas medidas para combater a epidemia e fazendo críticas em relação à resposta inicial chinesa, e como uma resposta às críticas da organização sobre a administração da crise pelo presidente. Assim, ameaçou cortar os fundos do país destinados à organi- 
zação, efetivando a ameaça uma semana depois (New York Times, 2020; Gawthorpe, 2020). Além disso, Trump culpa a China pela pandemia global e alega que o país faria "qualquer coisa que pudesse" para evitar sua reeleição em novembro. O presidente defende que a China deveria ter informado e agido antes em relação ao surgimento do vírus (Holland, 2020). Trump também acusa governadores democratas de atrasarem a reabertura econômica do país como forma de prejudicá-lo politicamente nas eleições (Mars, 2020). Os ataques a opositores do governo representam cerca de 15\% da amostra, e é centrada nos "Democrats" (Democratas) (65), na "Media" (Mídia) (57) e em alguns “Governors" (51) em específico. Entre os políticos citados com frequência estão Nancy Pelosi (ao menos 24 menções com diferentes nomes como "Crazy Nancy"), Joe Biden (cerca de 40 menções, como Sleepy Joe ou Biden), e o Governador de Nova Iorque Andrew Cuomo (cerca de 17 menções).

Após autoridades americanas de saúde decretarem estado de emergência, em 15 de março, seguiram-se recomendações para realização de teletrabalho, fechamento de escolas e evitar aglomerações. Ao longo do mês de março, Trump faz coro às medidas de contenção do vírus, pedindo que as pessoas fiquem em casa e respeitem o distanciamento social (17), ao passo que anuncia cooperação com governadores e prefeitos na distribuição de ventiladores e testagem. Ao final de março, Trump inicia a divulgação da hidroxicloroquina (12) como "cura" para a Covid-19, sem eficácia científica comprovada. Também ao final de março, sem diminuição dos números de contágio e aumento da pressão de empresários, Trump já alega que em breve o país estaria novamente "aberto para negócios", além de twittar "NÃO PODEMOS DEIXAR QUE A CURA SEJA PIOR QUE O PRÓPRIO PROBLEMA”, em letras maiúsculas, como já é seu costume em posts de assuntos de aparente urgência. Nesse momento, também aumenta o foco em políticas nacionalistas e de controle de migração citando a necessidade de fronteiras (33) e muros (7). Aos meados de abril os ataques aos governadores e prefeitos, que são contra a reabertura econômica, aumentam a tensão nos estados democratas, que passam a ter passeatas pedindo a reabertura do comércio e criticando políticas de isolamento social.

Protestos contra as medidas de confinamento foram realizados em diversos estados. Ganharam apoio entre políticos da direita e setores da mídia, além de personalidades públicas como Laura Ingraham, apresentadora da Fox News, que twittou o vídeo de um protesto dizendo "é hora de tomar sua liberdade de volta" para seus 3 milhões de seguidores (Gabbatt, 2020). Em 17 de abril, Trump encorajou abertamente esses protestos nos estados com ordens de quarentena, um dia após anunciar as medidas de abertura de seu governo. Assim, Trump postou tweets no estilo "LIBERATE MICHIGAN!", “LIBERATE MINNESOTA!”, estados onde governadores Democratas aplicaram medidas estritas de confinamento.

Em 23 de abril, Trump sugeriu que o uso interno de desinfetantes poderia ajudar no combate ao coronavírus. Como resultado, a linha de saúde recebeu diversas ligações com dúvidas em relação a isso, fazendo com que a Agência Federal de Gestão de Emergências (FEMA) tivesse que divulgar avisos de que estes produtos não deveriam 
ser ingeridos. Além disso, a Food and Drugs Administration (FDA) teve que advertir que o uso de hidroxicloroquina e cloroquina, recomendado diversas vezes pelo presidente, pode resultar em perigosos efeitos colaterais (Rogers et al., 2020). Um mês após Trump indicar estes dois remédios como tratamentos para a Covid-19, houve um aumento de mais de 46 vezes na quantidade de prescrições, chegando a 31.000 em 19 de março após a fala de Trump (Gabler \& Keller, 2020).

No dia 28 de maio de 2020, Trump postou no Twitter uma mensagem de pêsames aos que perderam familiares entre as mais de 100.000 vítimas. No dia seguinte, anunciou o encerramento das relações com a Organização Mundial da Saúde, culpabilizando a China pelo espalhamento do vírus. Dentro desse contexto, na Tabela 2 abaixo, podemos visualizar os 10 tweets de Donald Trump mais retweetados. É importante dimensionar as diferentes proporções de cada um dos presidentes nas redes sociais. Donald Trump tem mais de 85 milhões de seguidores e uma presença virtual muito mais forte que a do presidente Jair Bolsonaro - tanto pela média de publicações, quanto pelo alcance de seus tweets.

Tabela 2. Os 10 Tweets mais retweetados de Donald Trump durante o período

\begin{tabular}{|c|c|c|c|c|}
\hline & Data & Tweet & Retweets & Categoria(s) \\
\hline 1 & 29/mai & CHINA! & 153916 & $\begin{array}{c}\text { Nacionalismo/ Tom } \\
\text { populista }\end{array}$ \\
\hline 2 & 7/abr & $\begin{array}{l}\text { The W.H.O. really blew it. For some reason, funded largely } \\
\text { by the United States, yet very China centric. We will be } \\
\text { giving that a good look. Fortunately, I rejected their advice } \\
\text { on keeping our borders open to China early on. Why did } \\
\text { they give us such a faulty recommendation? }\end{array}$ & 113609 & $\begin{array}{l}\text { Nacionalismo/ } \\
\text { Ataque a opositores/ } \\
\text { Tom populista }\end{array}$ \\
\hline 3 & $17 /$ mar & The world is at war with a hidden enemy. WE WILL WIN! & 111168 & Tom populista \\
\hline 4 & 8/abr & $\begin{array}{l}\text { Extraordinary times require even closer cooperation } \\
\text { between friends. Thank you India and the Indian people } \\
\text { for the decision on HCQ. Will not be forgotten! Thank } \\
\text { you Prime Minister @NarendraModi for your strong } \\
\text { leadership in helping not just India, but humanity, in this } \\
\text { fight! }\end{array}$ & 110302 & $\begin{array}{c}\text { Acordo com outros } \\
\text { líderes de Estado }\end{array}$ \\
\hline 5 & 18/mai & REOPEN OUR COUNTRY! & 106551 & $\begin{array}{l}\text { Oposição a medidas } \\
\text { de contenção/ } \\
\text { Defesa da economia }\end{array}$ \\
\hline 6 & $22 / \operatorname{mar}$ & $\begin{array}{l}\text { RT @realDonaldTrump: HYDROXYCHLOROQUINE } \\
\text { \&amp; AZITHROMYCIN, taken together, have a real } \\
\text { chance to be one of the biggest game changers in the hi... }\end{array}$ & 103584 & $\begin{array}{l}\text { Defesa de } \\
\text { tratamentos sem } \\
\text { comprovação } \\
\text { científica }\end{array}$ \\
\hline 7 & $21 /$ mar & $\begin{array}{l}\text { HYDROXYCHLOROQUINE \&amp; AZITHROMYCIN, } \\
\text { taken together, have a real chance to be one of the biggest } \\
\text { game changers in the history of medicine. The FDA has } \\
\text { moved mountains - Thank You! Hopefully they will } \\
\text { BOTH (H works better with A, International Journal of } \\
\text { Antimicrobial Agents)..... }\end{array}$ & 103480 & $\begin{array}{l}\text { Defesa de } \\
\text { tratamentos sem } \\
\text { comprovação } \\
\text { científica }\end{array}$ \\
\hline
\end{tabular}


Tabela 2. (cont.)

\begin{tabular}{|c|c|c|c|c|}
\hline & Data & Tweet & Retweets & Categoria(s) \\
\hline 8 & $16 / a b r$ & $\begin{array}{l}\text { Crazy Nancy Pelosi deleted this from her Twitter account. } \\
\text { She wanted everyone to pack into Chinatown long after I } \\
\text { closed the BORDER TO CHINA. Based on her statement, } \\
\text { she is responsible for many deaths. She's an incompetent, } \\
\text { third-rate politician! https://t.co/uWNI7DCG3o }\end{array}$ & 98752 & $\begin{array}{l}\text { Ataque aos } \\
\text { opositores }\end{array}$ \\
\hline 9 & $13 / \mathrm{mar}$ & $\begin{array}{l}\text { It is my great honor to declare Sunday, March } 15 \text { th as a } \\
\text { National Day of Prayer. We are a Country that, throughout } \\
\text { our history, has looked to God for protection and strength } \\
\text { in times like these.... }\end{array}$ & 94098 & Outro \\
\hline 10 & $21 / \mathrm{abr}$ & $\begin{array}{l}\text { In light of the attack from the Invisible Enemy, as well } \\
\text { as the need to protect the jobs of our GREAT American } \\
\text { Citizens, I will be signing an Executive Order to } \\
\text { temporarily suspend immigration into the United States! }\end{array}$ & 92860 & $\begin{array}{l}\text { Defesa da } \\
\text { Economia/ } \\
\text { Nacionalismo }\end{array}$ \\
\hline
\end{tabular}

Fonte: Elaborado pelas autoras.

O primeiro tweet diz apenas "China”. Embora pareça inofensivo, foi publicado logo depois de os Estados Unidos haverem atingido 100 mil mortes na pandemia e de o presidente ter twittado que o coronavírus era "um péssimo presente" da China para o mundo ${ }^{[3]}$. O segundo tweet demonstra o acirramento das relações entre o presidente e a OMS - este tweet foi acompanhado pelo corte de verbas estadunidenses à organização - que em 29 de maio desembocaria em um total corte de relações. Os tweets número 3 "o mundo está em guerra contra um inimigo escondido: NÓS GANHAREMOS” e 5 "REABRAM O NOSSO PÁIS” (tradução livre) demonstram um pouco da estética populista de Donald Trump que faz tanto sucesso nas redes sociais: frases curtas, toda em caps locks, com uma mensagem simples pedindo unidade frente a um inimigo comum. Também demonstram dois momentos do presidente Trump: a primeira fase, em 17 de março, na qual apoiava as medidas de distanciamento social, e a segunda, em 18 de maio, quando já priorizava as medidas econômicas em detrimento do avanço da pandemia. O sexto e o sétimos posts mais compartilhados falam sobre o uso da hydroxocloroquina e azitromicina na cura da Covid-19. Tanto Trump como Bolsonaro foram verdadeiros "garotos propaganda" dos medicamentos, embora não sem nenhuma comprovação cientifica. $\mathrm{O}$ oitavo tweet mais compartilhado se trata de um ataque à senadora Nancy Pelosi, no qual Trump busca responsabilizá-la por convidar pessoas a visitarem China Town durante a pandemia. O décimo post mais compartilhado demonstra o nacionalismo exacerbado de Trump, ao passo que suspende a imigração nos Estados Unidos para "proteger os empregos" dos "grandes cidadãos americanos".

3. Disponível em:< https://twitter.com/realdonaldtrump/status/1266014911127306240> Acesso em: 9 de set. 2020 
Os Estados Unidos, conforme índices do V-Dem, é caracterizados como um país com médio risco de retrocesso democrático durante a pandemia do coronavírus. Cabe ressaltar que o país já se encontrava em processo de autocratização antes da pandemia, visto que já havia um enfraquecimento das instituições democráticas (Lührmann, Edgell \& Maerz, 2020). Um estudo do Comitê de Proteção aos Jornalistas (CPJ) aponta que os ataques de Trump à mídia, que acusa de distribuir "fake news", é um dos fatores que põe em risco a democracia, uma vez que "perigosamente enfraquece a verdade e o consenso em um país extremamente dividido" em um período de desafios sem precedentes trazidos pelo coronavírus (Farhi, 2020).

\section{Discussão dos resultados}

Conforme apresentado ao longo deste trabalho, ainda que em contextos diferentes de acordo com seus países, Donald Trump e Jair Bolsonaro apresentam uma série de atitudes, durante a crise do coronavírus, semelhantes a ser ressaltadas. Primeiramente, a negação da ciência aparece na escolha de ignorar recomendações da comunidade médica e científica, assim como de organismos internacionais, como a OMS, mas chega a seu limite quando os governantes recomendam tratamentos sem qualquer comprovação científica. Adicionado a isso, ambos presidentes estão entre os poucos governantes mundiais que politizaram a crise do coronavírus, utilizando-se de discursos que acentuam a polarização política. Como já é de costume, buscam inimigos para culpar, sendo estes qualquer um que não endosse ou apoie o que os líderes têm a dizer. Conforme vimos em Fuchs (2018), líderes demagogos tentam desviar as complexidades por trás das crises, transferindo sua culpa para outros (Fuchs, 2018). Desta vez Trump e Bolsonaro encontraram um novo alvo: os governadores e prefeitos localizados no espectro político oposto, que ao tentar proteger a população e o sistema de saúde com medidas de restrição, são acusados de tentar quebrar a economia e restringir liberdades individuais, claro que sempre com o objetivo maior de prejudicar a imagem dos presidentes, uma vez que os líderes populistas se apresentam como defensores dos interesses do povo (Urbinati, 2020). Assim, colocam-se como salvadores da pátria, ao justificarem suas ações como defesa dos trabalhadores e da liberdade, e vítimas, ao culparem outros poderes ou atores por não os permitirem que façam isso.

A mídia - acusada de gerar histeria e produzir fake news - continua como um dos principais focos, além dos já tradicionais adversários de esquerda (os Democratas para Trump e Lula e o PT para Bolsonaro). Percebe-se que isso ocorre através da midiatazação, processo que no caso dos líderes em questão ocorre através das redes sociais, em que se vê a utilização da política de espetáculo, com forte uso de propaganda (Pajnik \& Meret, 2018), que durante a pandemia ocorre não apenas pelo questionamento das informações trazidas por organizações políticas, científicas e de saúde, mas pela forma como as (des)informações são trazidas ao público como verdade. Somado o contexto de pós-verdade (Farkas \& Schou, 2018) a uma situação de pandemia, percebemos que o cenário pôde tornar ainda mais nocivo o papel das fake 
news e da desinformação, uma vez que impacta em vidas perdidas e em questão de saúde pública. Suas narrativas apresentam fortes e claras características populistas, que tomaram contornos específicos ao contexto da pandemia. Os efeitos mais significativos, em primeira ordem, podem ser facilmente observados pelas contrastantes divergências entre as perceções de indivíduos pertencentes a diferentes espectros políticos. Tanto no Brasil quanto nos Estados Unidos, apoiadores de Bolsonaro e Trump tendem a subestimar mais a seriedade da epidemia, disseminar desinformação, e se colocar em risco (e consequentemente a outros) uma vez que apresentam menor adesão às medidas de contenção do vírus.

Ao utilizar-se destas divergências, juntamente com a criação de inimigos, ambos os presidentes construíram narrativas que visam mobilizar e criar coesão entre seus apoiadores. No caso americano, as eleições encontram-se como o a principal motivação para tal, uma vez que Trump busca apoio para sua reeleição através da defesa da reabertura da economia, com foco também na volta à atividade de outros setores (como as igrejas). No caso brasileiro a crise institucional entre o Executivo e os outros poderes (Congresso, Judiciário e governos locais) é central, visto a inicial perda de popularidade de Bolsonaro somada a uma série de pedidos de impeachment que já se encontram no Legislativo, que levam o presidente a buscar apoio de alas do Congresso (no chamado Centrão), assim como de deslegitimar os que apontam irregularidades em seu governo. Entretanto, com a concessão do Auxílio Emergencial, Bolsonaro tem encontrado espaço para não apenas reconquistar sua popularidade, como também penetrar nas camadas vulneráveis antes ligadas à figura de Lula e ao PT, especialmente no Norte e Nordeste.

\section{Considerações finais}

Conforme visto ao longo do artigo, concluímos que tanto Bolsonaro quanto Trump utilizam-se das redes sociais e da política de espetáculo (Pajnic \& Meret, 2018) para trazer conteúdo ao público, utilizando-se centralmente do ambiente digital para tal. Ambos líderes possuem certas características de líderes autoritários (Levitsky \& Ziblatt, 2018) como no caso de Bolsonaro que convoca, no meio de uma pandemia, apoiadores às ruas para protestar contra as instituições democráticas do Legislativo e Judiciário, além de ter forte ligação com os militares, que coloca de modo crescente em posições técnicas do governo, como o próprio Ministério da Saúde e Trump que evoca a violência para conter a oposição, como no caso da onda de protestos após o incidente envolvendo o homem negro, George Floyd. Ainda assim, configuram-se como líderes que cada vez mais se direcionam a uma democracia populista (Urbinati, 2019) e dirigida pela mídia (Pajnic \& Meret, 2018), em que visam minar instituições intermediárias como os partidos políticos (que, por exemplo, Bolsonaro comumente refere-se como "velha política") e a mídia, e a audiência adquire um papel central uma vez que fornece legitimidade à retórica dos líderes, que é disseminada pelas redes sociais. Assim, conforme já concluído em trabalhos anteriores (Costa \& Bernardi, 2020), reafirmamos que ambos países estão adoecendo e morrendo por 
dois males: a Covid-19 e o discurso populista exacerbante de seus líderes. Para as próximas pesquisas, buscaremos aprofundar as análises das redes sociais, avaliando grafos de compartilhamento de tweets e interação com perfis de comportamento automatizado.

Data de receção: 10/09/2020

Data de aprovação: 22/12//2020

\section{Referências}

Al Jazeera. (2020a). Timeline: How the new coronavirus spread. Al Jazeera, 13 de maio de 2020. <https://www.aljazeera.com/news/2020/01/timeline-china-coronavirus-spread-200126061554884.html>.

Al Jazeera. (2020b). A timeline of the Trump administration's coronavirus actions. Al Jazeera, 23 de abril de 2020. <https://www.aljazeera.com/news/2020/04/timeline-trump-administration-coronavirus-actions-200414131306831.html>.

Andrade, H. (2020). Bolsonaro "monta" cenário para divulgar hidroxicloroquina em evento. UOL, 15 de julho de 2020. <https://noticias.uol.com.br/politica/ultimas-noticias/2020/07/15/bolsonaro-monta-cenario-e-usa-evento-do-planalto-para-divulgar-medicamento.htm>

Bitar, S. \& Zovatto, D. (2020). The impact of the coronavirus in Latin America’s future. International Idea Institute News, 2 de abril de 2020. <https://www.idea.int/news-media/news/ impact-coronavirus-latin-america-future $>$.

Carothers, T. (2020). The United States: Presidential Leadership, Polarization, and the Coronavirus. Carnegie Endowment for International Peace, 28 de abril de 2020.

Carvalho, R. \& Costa, F. (2020). Covid-19: Bolsonaro incentivou carreata contra isolamento social em Manaus. Uol Notícias, 30 de abril de 2020. <https://noticias.uol.com.br/politica/ultimas-noticias/2020/04/30/covid-19-bolsonaro-incentivou-carreata-contra-isolamento-social-em-manaus.htm>.

Cohen, J. (2020). Axios|SurveyMonkey poll: perceptions of coronavirus. <https://www.surveymonkey.com/curiosity/axios-coronavirus-perception/>.

Costa, A. \& Bernardi, A. (2020). Líderes populistas e a crise do coronavírus: comparações entre Estados Unidos e Brasil, Working Paper \#92, Observatório Político. <www.observatoriopolitico.pt>.

Corasaniti, N. (2020). Coronavirus Takes Over Political Advertising. The New York Times, 21 de abril de 2020. <https://www.nytimes.com/2020/04/21/us/politics/coronavirus-takes-over-political-advertising.html>.

Cucolo, E. (2020). Crise do coronavírus pode tirar até R $\$ 500$ bi do consumo. Folha de S. Paulo, 4 de maio de 2020. <https://www1.folha.uol.com.br/mercado/2020/05/crise-do-coronavirus-pode-tirar-ate-r-500-bi-do-consumo.shtml>

Falcão, M. \& Vivas, F. (2020). PGR pede ao STF inquéiro para investigar Weintraub por suposto racismo contra chineses. G1, 14 de abril de 2020. <https://g1.globo.com/politica/ noticia/2020/04/14/pgr-pede-ao-stf-abertura-de-inquerito-contra-weintraub-por-crime-de-racismo-contra-china.ghtml $>$. 
Farkas, J. \& Schou, J. (2018). Fake News as a Floating Signifier: Hegemony, Antagonism and the Politics of Falsehood. Journal of the European Institute for Communication and Culture, 25(3), 298-314.

Ferreira, P. \& Fragelli, R. (2020). Populismo estrutural. Valor Econômico, 20 de agosto de 2020. $<$ https://bibliotecadigital.fgv.br/dspace/bitstream/handle/10438/29603/populismo-central.pdf $>$.

Finchelstein, F. (2020). Para una história global del populismo: rupturas y continuidades. Conhecer: Debate entre o Público e o Privado, 10(24), 12-23.

Finchelstein, F. (2017). From fascism to populism in history. Oakland, CA: University of California Press.

Folha de S. Paulo. (2020). Instagram classifica como fake news postagem sobre coronavírus compartilhada por Bolsonaro. Folha de S. Paulo, 12 de maio de 2020. <https://www1. folha.uol.com.br/poder/2020/05/instagram-classifica-como-fake-news-postagem-sobre-coronavirus-compartilhada-por-bolsonaro.shtml>.

Forgey, Q. (2020). Trump on 'Chinese virus' label: 'It's not racist at all'. Politico, 18 de março de 2020. <https://www.politico.com/news/2020/03/18/trump-pandemic-drumbeat-coronavirus-135392>.

Fuchs, C. (2018). Digital Demogogue: Authoritarian Capitalism in the Age of Trump and Twitter. Northampton: Pluto Press.

Gabler, E. \& Keller, M. H. (2020). Prescriptions Surged as Trump Praised Drugs in Coronavirus Fight. The New York Times, 25 de abril de 2020. <https://www.nytimes.com/2020/04/25/ us/coronavirus-trump-chloroquine-hydroxychloroquine.html $>$.

Gabbatt, A. (2020). Protests against US stay-at-home orders gain support from rightwing figures. The Guardian, 16 de abril de 2020. <https://www.theguardian.com/world/2020/ apr/16/michigan-protest-coronavirus-rightwing-support>.

Gawthorpe, A. (2020). Trump's decision to cut WHO funding is an act of international vandalism. The Guardian, 15 de abril de 2020. <https://www.theguardian.com/commentisfree/2020/apr/15/trump-decision-cut-who-funding-international-vandalism-coronavirus $>$.

G1. (2020a). Bolsonaro discursa em Brasília para manifestantes que pediam intervenção militar. G1, 19 de abril de 2020. <https://g1.globo.com/politica/noticia/2020/04/19/bolsonaro-discursa-em-manifestacao-em-brasilia-que-defendeu-intervencao-militar. ghtml>.

G1. (2020b). Bolsonaro volta a apoiar ato antidemocrático contra o STF e o Congresso, em Brasília. G1, 3 de maio de 2020. <https:/g1.globo.com/fantastico/noticia/2020/05/03/ bolsonaro-volta-a-apoiar-ato-antidemocratico-contra-o-stf-e-o-congresso-em-brasilia.ghtml>.

Holland, S. (2020). Exclusive: Trump says China wants him to lose his re-election bid. Reuters, 30 de abril de 2020. <https://www.reuters.com/article/us-usa-trump-china-exclusive/ exclusive-trump-says-china-wants-him-to-lose-his-bid-for-re-election-idUSKBN$22 \mathrm{C} 01 \mathrm{~F}>$.

Jornal Nacional. (2020). Bolsonaro pede na TV a 'volta à normalidade' e fim do 'confinamento em massa' e diz que meio de comunicação espalham 'pavor'. G1, 24 de março de 2020. 
<https://g1.globo.com/politica/noticia/2020/03/24/bolsonaro-pede-na-tv-volta-a-normalidade-e-fim-do-confinamento-em-massa.ghtml>.

Levitsky, S. \& Ziblatt, D. (2018). Como as Democracias Morrem. Rio de Janeiro: Zahar.

Lührmann, A., Edgell, A. B., \& Maerz, S. F. (2020). Pandemic Backsliding: Does Covid-19 Put Democracy at Risk? V-Dem Policy Brief, 23.

Libório, B. \& Fávero, B. (2020). Como a desinformação sobre cloroquina se multiplicou no Twitter após aval de Bolsonaro à droga. Aos Fatos, 25 de março de 2020. <https://www. aosfatos.org/noticias/como-desinformacao-sobre-cloroquina-se-multiplicou-no-twitter-apos-aval-de-bolsonaro-droga/>.

Mars, A. (2020). Trump acusa governadores democratas de atrasarem reabertura para prejudicá-lo politicamente. El País, 12 de maio de 2020. <https://brasil.elpais.com/ internacional/2020-05-12/trump-acusa-governadores-democratas-de-atrasarem-reabertura-para-prejudica-lo-politicamente.html?fbclid=IwAR053OoXatV8W2ZJvp6D1KSKdrr-jYFrYwMr7x70XkqmiFMZywB5-3027xA>.

Matoso, F. \& Rodrigues, M. (2020). Coronavírus: Bolsonaro diz na TV que não há razão para pânico ainda que problema se agrave. G1, 6 de março de 2020. <https://g1.globo.com/ bemestar/coronavirus/noticia/2020/03/06/ainda-que-o-problema-possa-se-agravar-nao-ha-motivo-para-panico-diz-bolsonaro-sobre-coronavirus.ghtml>

Mazuí. G. (2020). Mandetta anuncia em rede social que foi demitido por Bolsonaro do Ministério da Saúde. G1, 16 de abril de 2020. <https://g1.globo.com/politica/noticia/2020/04/16/mandetta-anuncia-em-rede-social-que-foi-demitido-do-ministerio-da-saude.ghtml>

Mazzetti, M., Barnes, J. E., Wong, E., \& Goldman, A. (2020). Trump Officials Are Said to Press Spies to Link Virus and Wuhan Labs. The New York Times, 30 de abril de 2020. <https:// www.nytimes.com/2020/04/30/us/politics/trump-administration-intelligence-coronavirus-china.html? referringSource=articleShare $>$

Mena, F. DeLuca, N., \& Yukari, D. (2020). Em menos de 5 meses, coronavírus escreve a sua biografia em 181 países. Folha de S. Paulo, 13 de maio de 2020. <https://www1.folha. uol.com.br/mundo/2020/05>.

Mudde, C. (2020). Will the coronavirus 'kill populism'? Don't count on it. The Guardian, 27 de março de 2020. <https://www.theguardian.com/commentisfree/2020/mar/27/coronavirus-populism-trump-politics-response $>$.

Mudde, C. \& Kaltwasser, C. R. (2017). Populism: A Very Short Introduction. New York: Oxford University Press.

Murakawa, F. (2020). Bolsonaro provoca aglomeração e faz propaganda da cloroquina no Alvorada. Valor Econômico, 19 de julho de 2020. <https://valor.globo.com/brasil/noticia/2020/07/19/bolsonaro-provoca-aglomerao-e-faz-propaganda-da-cloroquina-no-alvorada.ghtml>.

New York Times. (2020). Trump attacked the W.H.O. For its handling of the coronavirus outbreak and its criticisms of his policy. The New York Times, 7 de abril de 2020. $<$ https://www.nytimes.com/2020/04/07/world/coronavirus-updates-news-live.html\#link$-5 \mathrm{e} 3 \mathrm{~b} 2 \mathrm{c} 82>$. 
Pajnik, M. \& Meret, B. (2018). Populism and the web: Communicative Practices of Parties and Movements in Europe. London/New York: Routledge.

Quinnipiac University. (2020). March 9, 2020 - Biden Crushes Sanders In Democratic Race, Quinnipiac University National Poll Finds; More Disapprove Of Trump's Response To Coronavirus. <https://poll.qu.edu/national/release-detail?ReleaseID=3657 https:// poll.qu.edu/national/release-detail?ReleaseID=3657>.

Rachman, G. (2020). Jair Bolsonaro's populism is leading Brazil to disaster. Financial Times, 25 de maio de 2020. <https://www.ft.com/content/c39fadfe-9e60-11ea-b65d$-489 \mathrm{c} 67 \mathrm{~b} 0 \mathrm{~d} 85 \mathrm{~d}>$.

Rosseto, G., Carreiro, R. \& Almada, M. (2013). Twitter e comunicação política: limites e possibilidades. Compolítica v.3, n. 2, p.189-216.

Statista. (2020). Leading countries based on number of Twitter users as of July 2020. <https:// www.statista.com/statistics/242606/number-of-active-twitter-users-in-selected-countries/>.

UN. (2020). UN tackles 'infodemic' of misinformation and cybercrime in COVID-19 crisis. The United Nations Department of Global Communications (DGC). <https://www. un.org/en/un-coronavirus-communications-team/un-tackling-\%E2\%80\%98infodemic\%E2\%80\%99-misinformation-and-cybercrime-covid-19>.

Urbinati, N. (2019). Me the people: how populism transforms democracy. London: Harvard University Press.

Urbinati, N. (2020). The Pandemic Hasn't Killed Populism: After Lockdowns, Demagogues Will Likely Resurge. Foreign Affairs, 6 de Agosto de 2020. < https://www.foreignaffairs. com/articles/united-states/2020-08-06/pandemic-hasnt-killed-populism.

Uribe, G. \& Daniel, C. (2020). Quem é de direita toma cloroquina, quem é de esquerda, Tubaína, diz Bolsonaro. Folha de S. Paulo, 19 de maio de 2020. <https://www1.folha.uol. com.br/equilibrioesaude/2020/05/bolsonaro-diz-que-novo-protocolo-sobre-cloroquina-sera-assinado-nesta-quarta-feira.shtml>.

Van Djick, J. (2013) Culture of Connectivity: A Critical History of Social Media. Oxford: Oxford University Press.

Zarocostas, J. (2020). How to fight an infodemic. The Lancet, World Report, 395(10225), 676, 29 de fevereiro de 2020. <https://www.thelancet.com/journals/lancet/article/PIIS0140-6736(20)30461-X/fulltext>.

Zurcher, A. (2020). Coronavirus: Who Trump supporters blame for virus 'hysteria'. BBC News, 11 de março de 2020. <https://www.bbc.com/news/world-us-canada-51840227>.

Weterman, D. (2020). Após 100 mil mortes por covid-19, Bolsonaro lamenta óbitos 'seja qual for a causa'. Estadão, 9 de agosto de 2020. <https://brasil.estadao.com.br/noticias/geral,apos-100-mil-mortes-por-covid-19-bolsonaro-lamenta-obitos-seja-qual-for-a-causa,70003393413>.

WHO. (2020). WHO Timeline - COVID-19. World Health Organization, 27 de abril de 2020. $<$ https://www.who.int/news-room/detail/27-04-2020-who-timeline---covid-19>.

Worldometer. (2020). Covid-19 Coronavirus Pandemic. <https://www.worldometers.info/coronavirus/>. 


\title{
Sobre os autores
}

andressa liegi vieira costa é mestre em Ciência Política pelo Instituto Superior de Ciências Sociais e Políticas (ISCSP) da Universidade de Lisboa. Pesquisadora do Laboratório de Estudos de Mídia e Esfera Pública (LEMEP) da Universidade do Estado do Rio de Janeiro (UERJ) no projeto 'Manchetômeto', e Pesquisadora do Núcleo de Pesquisas sobre a América Latina (Nupesal) da Universidade Federal do Rio Grande do Sul (UFRGS). É também bacharel em Ciências Sociais pela UFRGS e bacharel em Relações Internacionais pela ESPM (Porto Alegre/RS - Brasil). Suas áreas de investigação incluem Brasil, América Latina, comportamento político, participação política, cultura política, democracia, opinião pública e redes sociais. [https://orcid.org/0000-0002-3655-1387]

ana julia bonzanini bernardi é doutoranda em Ciência Política pelo Programa de Pós-Graduação em Ciência Política (PPGCP) da Universidade Federal do Rio Grande do Sul (UFRGS). Pesquisadora visitante no Núcleo de Pesquisas sobre Movimentos Sociais (NPMS) da Universidade Federal de Santa Catarina (UFSC), e Pesquisadora do Núcleo de Pesquisa sobre a América Latina (Nupesal) da Universidade Federal do Rio Grande do Sul (UFRGS). É também mestre em Ciência Política e bacharel em Políticas Públicas pela UFRGS. Suas áreas de investigação incluem Brasil, Améria Latina, comportamento político, cultura política, democracia, políticas públicas, socialização política, opinião pública e redes sociais.

[https://orcid.org/0000-0001-7768-6264]

\begin{abstract}
About the authors
ANDRESSA LIEgI VIEIRA Costa holds a Master's degree in Political Science by the Institute of Political and Social Science (ISCSP) from the University of Lisbon. She is a Researcher at the Laboratory of Media and Public Sphere Studies (LEMEP) from Rio de Janeiro State University (UERJ) on the project 'Manchetometro' and Researcher at the Research Center on Latin America (Nupesal) from the Federal University of Rio Grande do Sul (UFRGS). She also holds a Bachelor's degree in Social Sciences by UFRGS and a Bachelor's degree in International Relations by ESPM (Porto Alegre/RS - Brazil). Her areas of research include Brazil, Latin America, political behavior, political participation, political culture, democracy, public opinion and social media. [https://orcid.org/0000-0002-3655-1387]
\end{abstract}

ANa JUlia bonzanini bernardi is a PhD student in Political Science by the Graduate Program in Political Science (PPGCP) at the Federal University of Rio Grande do Sul (UFRGS). Visiting researcher at the Center for Research on Social Movements (NPMS) at the Federal University of Santa Catarina (UFSC), and Researcher at the Center for Research on Latin America (Nupesal) at the Federal University of Rio Grande do Sul (UFRGS). She also holds a Master's Degree in Political Science and a Bachelor degree in Public Policy by UFRGS. Her areas of research include Brazil, Latin America, political behavior, political culture, democracy, public policies, political socialization, public opinion and social networks.

[https://orcid.org/0000-0001-7768-6264] 